DOI: https://doi.org/10.47405/mjssh.v6i5.801

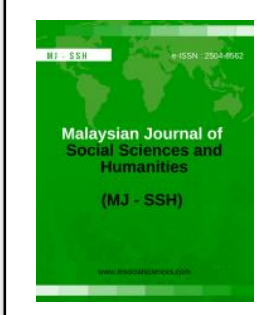

Malaysian Journal of Social Sciences and Humanities (MJSSH)

Volume 6, Issue 5, May 2021

e-ISSN : 2504-8562

Journal home page:

www.msocialsciences.com

\title{
An Analysis of Sentence-Like Utterances of IELTS Mock Speaking Test Scripts
}

\author{
Shasthrika Baskaran1, Mohammad Nor Afandi bin Ibrahim², Isai Amutan Krishnan, Vasithra A/P \\ Devamanickam $^{4}$, Nancy Andrew ${ }^{5}$, Shelen Aderina Kok ${ }^{6}$, Saravanan Munian ${ }^{7}$, Manickavasagar \\ Govindasamy ${ }^{8}$, Hee Sio Ching 9 , Vasudevan Naidu Kanan ${ }^{10}$ \\ 1Wisma RnD University of Malaya, Jalan Pantai Baharu, Taman Bukit Pantai, 59100 Kuala Lumpur, Wilayah \\ Persekutuan Kuala Lumpur \\ ${ }^{2}$ Jabatan Bahasa Inggeris, Akademi Pengajian Bahasa, UiTM Cawangan Melaka, Kampus Alor Gajah, Km 26, Jalan Lendu, \\ 78000 Alor Gajah, Melaka \\ ${ }^{3}$ Faculty of Languages and Linguistics, University Malaya, 50603 Kuala Lumpur \\ ${ }^{4}$ Faculty of Business and Accountancy, University Malaya , 50603 Kuala Lumpur \\ 5University Malaya, 50603 Kuala Lumpur \\ 6PG Kampus Kent Peti Surat 289207 Tuaran, Sabah \\ ${ }^{7}$ SRJKT Ganesar Serdang, Kedah \\ 8Faculty of Languages and Linguistics, University Malaya, 50603 Kuala Lumpur \\ ${ }_{9}^{9}$ ELM Business School, HELP University, Jalan Sri Semantan 1, Off Jalan Semantan, Bukit Damansara, 50490 Kuala \\ Lumpur \\ ${ }^{100}$ 'Connor's Engineering Sdn. Bhd. Bagunan O'Connor No.13 Jlaan 223, 46100 Petaling Jaya, Selangor
}

Correspondence: Isai Amutan Krishnan (amuthanisai@gmail.com)

\begin{abstract}
The present study examines non-Malaysian candidates' performance in an IELTS mock speaking test with regards to their use of different types of sentence structure utterances. Audio recorded data was obtained from eight students of three different levels of proficiency, namely; foundation, intermediate and advanced, in which thereafter an analysis was carried out using Radford (1990; 1997) sentence types. A semi-structured interview was also employed to gauge the candidates' opinions on answering the test questions as well the interlocutor's views on the candidates' performance. The test was conducted by an IELTS trained interlocutor. It was found that most candidates were able to understand the questions, their responses were mainly simple sentence utterances indicated by many disjointed and choppy ideas. The semi-structured interview answers show that most candidates' high level of nervousness and anxiety caused them not to be able to speak fluently, and as a result, their ideas were expressed in simple sentence structures that lacked logical coordination. It is hoped that the findings of the present study would help the current IETLS course module developers to integrate lessons on the different types of sentence structures in training test candidates to express complete and complex structured responses.
\end{abstract}

Keywords: sentence structures, IELTS, speaking, test

\section{Introduction}

Most of us are aware that English is considered globally, the lingua franca in many fields. Such as scientific research, international business, politics, communication and social media. The language is the most commonly used in the world by many people as well as international institutions, like the 
United Nations, IMF, ASEAN, and OPEC. The extensive usage of it internationally has created an impetus for many to master the language in order to further their education, improvement of job prospects and better business transactions. The fact that the premier universities of the world like Oxford, Harvard and even NUS are located in the English-speaking countries, such as the UK, USA and Singapore is indicative of the needs to master the language in order to gain entry to those institutions.

The year 1980 marked the transformation of the English Proficiency Test Battery into the English Language Testing System (henceforth ELTS) and denoted a move away from a more conventional arrangement of language assessment, by establishing a specifically issue based speaking sub-test by way of personal interviews, manifesting communicative language education (Gallois, Cindy, Giles, \& Howard, 2015). Upon completion of the IELTS validation study in 1987, assigned by Cambridge English and the British Council, there was a broadening of international engagement with the inclusion of the International Development Program Education Australia (IDP Australia) in the new arrangement and the IELTS (henceforth IELTS), in its initial configuration, was executed in 1989. There was agreement that the speaking sub-test should be maintained, while the subject matter was to remain general in layout. Nevertheless, appraisal procedures were limited to ascertain internal uniformity and the validity of test takers' achievement, and evaluators were governed by straightforward integrated band scales that were at best reliable.

Since then, the IELTS test has been created to accommodate the requirements outlined above as well as to gauge and afford information regarding the applicants' standard of English. The students will then be categorised according to the level achieved in English proficiency based on specific band scores of the IELTS testing organisation in four equally weighted areas, namely; reading, writing, speaking and listening.

The test too is also broadly accepted as a large-scale ESL test offering exhaustive tests for students, in relation to reading, writing, listening and speaking elements. More than 150 million students in the world over, including 300,000 from mainland China alone took the IELTS in 2011,48 test centres were provided for the candidates in China Mainland in which the Chinese make up about $50 \%$ of IELTS students from the Asian region (ref?). Over the years, there has been exponential growth in the number of candidates sitting for the IELTS, including large numbers of repeaters. This is because, many of the candidates wanting to pass IELTS are keen to work or immigrate to English speaking countries and a large number of these students are from international joint education programs of different universities (Yu, 2014).

Broadly speaking, students and others in China are keen to hone their English-speaking skills (Kawai 2008) and while most around the world want to upscale their speaking proficiency in the language (Richards and Renandya 2002). Nevertheless, the majority of language students face major hurdles in improving their skills to converse in a second or foreign language. Among the problems are lack of good vocabulary and proper grammar (Celce-Murcia \& Olshtain 2000), little opportunities of using the language inside and outside classroom (Pawlak, Waniek-Klimczak, \& Majer 2011) and high level of anxiety particularly in oral production (Horwitz, 2008). More so, the apprehension about speaking adequately in a second language do not only affect students, but non-native teachers of English as well inform of a second or foreign language as they tend to shun speaking and other interactive and communicative teaching programs because of anxiety (Li 1998; Littlewood, 2007). In order for students to understand and perform better in IELTS, Chris (2015) provided ten examples of mistakes that students should avoid when taking the IELTS speaking exam and the major one involve expressing ideas completely.

An example of such incomplete idea expression is when asked what the candidate likes to do during free time, the response tended to be for instance, 'I like to play', I like to play badminton' and 'I like to play football', which considered simple ideas. These two answers are correct in grammar; but they lack comprehensive thoughts (Magoosh, 2018). Similarly, there was another answer which shows a comprehensive thought. 'Basically, I like helping my parents as we have our own family business. At the same time, I help my brother and sister to comprehend their homework', in which the examiner's 
comment is that the above answer is an appropriate one and could see the candidate use moderate vocabulary, as well as fluency, and hardly could grammar errors be seen.

Although, the candidates may speak grammatically correct English, their incapability of expressing ideas completely in structure has to be looked into. As discussed earlier, many researchers found that IELTS candidates have failed to construct varied sentence structures well and express their comprehensive thoughts; thus, the present study aims at examining how IELTS candidates use sentence structures in expressing their thoughts in IELTS mock speaking test.

\section{Literature Review}

\section{Overview of IELTS speaking test}

The IELTS speaking test which takes about 11 to $14 \mathrm{~min}$ to complete comes in three parts, and the interview is conducted by a qualified examiner. The first part, which takes about 5 minutes (introduction), consists of a written introduction and verification of the student's credentials followed by questions regarding the student's biodata, hobbies and other simple matters. (Seedhouse \& Nakatsuhara 2018). The second part (long turn) which last for about 4 minutes involves the student speaking for about 2 minutes on a subject selected by the examiner with a minute given to the student to prepare prior to the conversation. The examiner concludes part 2 by asking the student a few simple questions. To ensure that the tests are equally fair to all students, the examiners follow some stringent script in both parts 1 and 2 (Seedhouse \& Nakatsuhara 2018). The third part (two-way discussion), takes about 5 minutes and involves students discussing additional conceptual topics connected to topics in part 2. In contrast to part 1 and 2, the examiners might reshape the ranked question in the part 3 in an attempt to match the standard of the student. More so, students are required to apply a variety of language applications in part 3, ranging from clarifying and illustrating to crafting assumptions (Taylor 2007; Shohamy, 1994; Yoshida-Morise, 1998). Students are evaluated on four criterions: smoothness and consistency, lexical supply grammar choice, and correctness, and intonation (see Seedhouse \& Nakatsuhara 2018 for further details).

There is research which has been done to validate the IELTS speaking test by investigating some elements affecting students' performance in the test. These comprise the test layout or design (Brown 2006; Iwashita \& Vasquez 2015), timing (Wigglesworth \& Elder 2010) and subject (Khabbazbashi 2017).

Other researchers have studied the examiners and the scoring system (Carey \& Mannell 2009). Currently, only Huang (2013) examined the deliberate procedures influencing student presentation. Many of the investigations focused on the candidates' presentation in the entire test or just part 2 of the speaking test (Iwashita \& Vasquez 2015; Wigglesworth \& Elder 2010). Although, all three parts were examined, very little attention was given to part 3 of the IELTS test, in which Quaid (2018), stresses that its unstructured state offers 'examiners with a clearer denotation of real performance and grade' in comparison to parts 1 and 2 (p. 7).

\section{Strategies of IELTS Speaking Test}

Throughout a test, candidates utilise three forms of approaches: (1) language learner approaches; (2) test management approaches, and (3) test wiseness (Cohen, 2014). Language learner approaches help candidates in prompt the essential language for attack. The latter two approaches, test management and test wiseness are test-taking approaches. Test management approaches are deliberate acts and judgements that assist test candidates react to a test component or assignment significantly. They are utilised to trigger test takers' assignment-linked language awareness or aptitude and are consequently construct-relevant. On one hand, test wiseness approaches, , entail applying information regarding the test design and secondary factors instead of linguistic skill in concluding a test brief. These two approaches are construct irrelevant. The scale to which construct relevant and irrelevant approaches 
are applied, Cohen (2014) contends shapes the cogency of a test, in which many investigators have applied various means to determine test takers' approaches.

The most frequently applied technique is the prompted recall (Huang 2013; Huang 2016; Phaiboonnugulkij \& Prapphal 2013; Swain, Huang, Barkaoui, Brooks, \& Lapkin, 2009). Also, semistructured interviews were utilised by Swain et al. (2009) to elucidate information from prompted recalls interviews carried out previously. Huang (2013) obtained information from students' videorecorded speaking test' to confirm recognisable observable approaches that were absent in their prompted recall sittings (p. 11). Lastly, obtaining data by means of prompted recall, an improvised strategy in expressing the ideas of answering the question should not be in disjoined ideas (Huang, 2016).

\section{Strategic Competence in Speaking Test}

Attempts to describe and identify the intricacy of a student's language skills have been identified by means of different schemes of multi-componential designs (e.g. Bachman1990; Bachman \& Palmer 2010; Canale \& Swain 1980). For instance, both Canale and Swain (1980) as well as Bachman and Palmer (2010), in their designs incorporated linguistic (grammatical, sociolinguistic and pragmatic knowledge) and non-linguistic elements (skills on appropriate application of the language) identified as strategic competence. Previous designs portrayed strategic competence as performing two tasks in an execution: (i) to treat pending communication issues owing to test takers' grammatical and pragmatic weaknesses, as well as (ii) to improve communication (Canale, 1983; Canale \& Swain 1980). Based on detailed studies in cognitive psychology and speech construction, Bachman (1990) describes that strategic competence includes cognitive practices that control the application of language. Also, Bachman and Palmer (2010), has broaden the language function in communicative competence to incorporate meta-cognitive approaches which managed cognitive developments and interacted with test takers' own issues, like language and current knowledge, qualities and perceptive design. While these designs reinforce strategic competence in speaking ability, and practical substantiation which is deficient on its functions in a speaking test when a speaker speaks confidently to portray the proficiency.

\section{Past Studies on Speaking Test}

Swain et al. (2009), conducted a study on the test takers' approach in two impartial (speaking only) and four coordinated integrated (listening, reading and speaking or listening and speaking) jobs of the TOEFL-iBT (TOEFL internet-Based Test). All 30 individuals undertook prompted recall, following each job and approaches from five classes was considered: emotion, method, cognitive, communication and meta-cognitive. Metacognitive, communication and cognitive approaches were most commonly applied. Utilising the Spearman's rho non-parametric test, it was established that certain personal approaches had adverse parallel correlation with test marks (self-correcting, attending). This was ascribed to certain approaches that required greater utilisation of thinking processes than others while talking.

Huang (2016), investigated the way certain approaches influenced test takers' achievement in six assignments of the TOEIC speaking test, as well as a computer-based test. From the 215 Taiwanese candidates who sat for the test, 8 were selected for the prompted recall. A self-made- 41 -article list was made out to gather measurable information. The list was centred on the classification from earlier investigations (Barkaoui et al. 2013; Huang 2013; Swain et al. 2009). Huang (2016), focused on three comprehensive strategy groups, namely; cognitive, communication and emotion, utilising investigative factor analysis and structural equalling model (SEM) to examine the information. He stated that cognitive and communication approaches had a positive effect on presentation. Communication approaches influenced presentation more precisely than cognitive approaches. In contrast to Swain's et al. (2009) and Barkaoui's et al. (2013) studies, Huang (2013), examined test takers' strategy utilisation in the IELTS speaking test. Professing to study strategy utilisation in testing and non-testing conditions, Huang (2013) split her 40 Chinese-speaking university students into two uniform teams. Using MANOVA and ascertained that test takers used different approaches in testing and non-testing 
conditions. He further concluded that contrasting approaches were conjured in all three assignments. Students in the testing team made greater use of strategy and meta-cognitive approaches in task 3 in contrast to students in the non-testing team. While, the psychometric, ethnographic and communication analysis study have divulged a great deal of information regarding the essence of language speaking in recent times. Since then scholars have not discerned any change in pattern in the techniques of teaching and learning of speaking abilities, and the best way to teach speaking competence continues to be focal point on sentence formats. At the same time, there is a dearth of factual data available for chronicling students' insights and practice in speaking ESL or EFL in various educational frameworks, in contrast to reading, writing and listening.

Since 1990, Radfold has conducted a few studies relating to the sentences structure by monolingual, bilingual and language-disordered children, language structure of colloquial English based on syntactic theory-sentence structures. Among his major findings are that sentence structures envelop an approach in building a sentence from basic, compound, complex and compound-complex with the utilisation of subject, verb, protest, subordinate and free clauses that are combined in talked frame.

Based on Radfold's $(1990 ; 1997)$ studies, a number of studies have been carried out by others like Verspoor and Sauter (2000) on English sentence examination, Steffani (2007), in distinguishing proof of implanted and conjoined complex sentences. Demirezen (2012) and Sundari (2013) investigation of straightforward sentence designs, Hart, Grigal, and Weir (2010) on promising expressions, Adaninggar (2017) on the authority of complex sentences among pre-service instructors. Furthermore, Ika, Hermawati and $\mathrm{Zul}$ (2018) on the investigation of compound sentences in students' composing and Shkelqim (2017) on the work of Albanian and English sentences. However, all these studies have underscored the investigation of both spoken and witten by using sentence structures. Nevertheless. those of Radford, Felser and Boxell (2012) and Collins and Radford (2015), have accentuated the significance of sentence structure investigation within the spoken more. However, it has to be equally treated in spoken and written.

Adaninggar (2017), found that it is either in spoken or written, longer sentences or articulations are required to depict an author writer's or a speaker's capability. In any case, Radford $(1990 ; 1997)$ contended that within the intuitive complexity of the expressions, well-structured clauses or sentence structures depict a speaker's capability. In a comparative vein, Sundari (2013) found that simple composed sentences can be acknowledged but might not be in talked frame, particularly in formal setting. Be that as it may, it all depends on the speaker's capability. Similarly, Dulay, Burt and Krashen (1982) as well as Krashen and Terrell (1983) accepted that one ought to express his or her thoughts either composed or talked seriously, coupled with the capacity to build compound-complex sentences to communicate messages totally. Their claims are backed by Sarangi and Candlin (2011), who agree that great capability is required within the proficient setting to communicate the expecting meaning in talked intuitive.

Radford (1990;1997), instituted a study of sentence structures (Simple, Compound, Complex and Compound-Complex sentences), i.e. the methodology involved in sentence construction. While the composition of sentences is usually tested in written work, thus very little focus has been accorded to speaking skills. As such, the ability to construct sentences is vital to articulate thoughts clearly and precisely in the suitable forum, particularly in oral tests. Table 1 below show examples of sentence structures.

Table 1: Types of Sentence Structures

\begin{tabular}{llll}
\hline No & $\begin{array}{l}\text { Types of } \\
\text { Sentence }\end{array}$ & Definition & Examples \\
\hline 1 & Simple Sentence & A simple sentence consists \\
& & $\begin{array}{l}\text { of one autonomous phrase. } \\
\text { What's an "autonomous } \\
\text { phrase"? It's }\end{array}$ & $\begin{array}{l}\text { Robert doesn't consume meat. } \\
\text { My brother and I visited the } \\
\end{array}$ \\
& one topic accompanied by & $\begin{array}{l}\text { supermarket last night. } \\
\text { This recent laptop computer has }\end{array}$
\end{tabular}


a verb or verb phrase. It conveys only one idea.

2

Compound

Sentence

3

Complex

Sentence

CompoundComplex
A compound sentence has

two autonomous phrases

linked by a connecting term

(and, but, or, so, yet,

however).

Every autonomous phrase can be a sentence on its own, but we link them with a connecting expression:

A complex sentence has one autonomous phrase and more than one contingent phrases.

A contingent phrase cannot be a standalone sentence.

A compound-complex sentence is made up of 3 or more phrases: 2

autonomous and a minimum of 1 contingent phrase. already stopped working two times. Observe that a "simple sentence" need not be short. The topic could be a single phrase like "I" or "Robert," or it could be two topics like "my brother and I," or it could be manifold phrases relating to one person/object, like "This original laptop computer."

I 'm joyful, but my children are forever grouchy.

Robert doesn't like meat, so Barbara cooked a particular vegetarian plate for him.

My brother and I went to the supermarket last night, but we didn't do any purchase.

This original laptop computer has already broken down two times, and I don't know the reason. Observe that each sentence has TWO topics and TWO verb phrases.

I'm joyful, although I don't earn much.

Robert, a pal known to me since high school, doesn't consume meat. Upon reaching home from the workplace, my brother and I went to the supermarket last night.

This original laptop computer, which I purchased yesterday, has already broken down two times.

I'm joyful, although though I don't earn much., but my children are forever grouchy because we are unable to purchase the latest toys. Autonomous phrases: "I'm joyful" and "my children are forever grouchy" išpepicicontingent phrases: "although I don't earn much" and "since we are unable to purchase the latest toys" "LSEP: Linking word: "but" Robert, a pal known to me since high school, doesn't consume meat-so Barbara prepared a particular vegetarian plate for him.

Autonomous phrases: "Robert doesn't consume meat" and "Barbara prepared a particular vegetarian plate for him":ichepicontingent phrase: "a pal known to me since high school" iLEP:Linking word: "so" Upon reaching home from the workplace, my brother and I went to the supermarket last night, while my 
sister stayed home and studied. Independent clauses: "My brother and I went to the supermarket last night" and "my sister stayed home and studied" Contingent clause: "Upon reaching home from the workplace" Linking word: "while" This original laptop computer, which I purchased yesterday, has already broken down two times; but, I don't know why.

Autonomous phrases: "This original laptop computer has already broken down two times" and "I don't know why" Contingent phrase: "which I purchased yesterday "Linking word: "however"

Source: Transformational Grammar and Syntactic Theory and Structure of English (Radford, 1990; 1997)

Table 1 illustrates the meaning of sentence structures based on Radford's (1990;1997) theory. Sentence structures are made up of simple, compound, complex and on the basis of these meanings, some sentence composition examples have been shown to produce a better knowledge of sentence compositions. He further postulates that, it is vital to separate one's sentence constructions to establish distinctness between your spoken and written words, to choose and merge sentence compositions for diverse purposes, and also to apply various forms of sentences to highlight thoughts. Radford $(1990 ; 1997)$, focuses more on written rather than spoken language and there appeared to be a lack of knowledge and skill in the construction of combination sentences of speaking as indicated by Chris (2015), that speaking should be also in a comprehensive thought.

As emphasised in the introduction section, many students are weak in forming complete and varied utterances in IELTS speaking tests. Hence, for the current research, Radford's sentence structure constructions will be employed in the analysis of the candidates' speaking transcriptions in investigating their speaking skill competence in an IELTS mock speaking test.

\section{Methodology}

\section{Setting}

The current research was carried out in one educational institution in Kuala Lumpur, Malaysia. The institution offers various English courses and one of them is IELTS preparatory course for students who intend to pursue their tertiary education in Malaysian public universities. Consents were obtained from the department head as well as the participants in conducting the present study. The name of the institution and students 'names were not allowed to be revealed. The IELTS mock speaking test was allowed to be recorded. Although, the semi-structured interview sessions with the students and interlocutor are not.

\section{Sampling}

There were eight candidates and one interlocutor (the person who conducted the mock speaking test) who participated. In any qualitative studies, especially involving oral communication and in-depth interview, the number of participants is always smaller than that of the quantitative studies, in which five to fifty participants are deemed adequate (Mason, 2010; Baker, Edwards, 2012). Thus, the number of participants in the present study was adequate to be undertaken. The interlocutor is a Malaysian, 
while the candidates are Chinese nationality, aged between 18 to 21 years old. They sat for an IELTSoriented placement test which had three components namely, grammar, reading comprehension and writing before starting the actual IELTS preparatory course. Based on the placement test results, three were assigned to foundation level, two to intermediate, while the remaining two to advanced one. In which candidates who score 6.5 and above in the actual IELTS test will be allow to qualified to pursue their tertiary studies in Malaysia public universities.

\section{Instrument}

Audio recording method was used in the present study. A digital audio voice recorder, SK 012 4GB Dictaphone MP3, was placed in the middle of the table and it was operated by the interlocutor during the IELTS-oriented speaking test.

\section{Data Collection}

The spoken test data was collected by the interlocutor who conducted the IELTS mock speaking test. The interlocutor has attended a number of trainings of IELTS speaking test, which was organised by British Council in Malaysia. Therefore, the interlocutor is qualified to conduct the IELTS mock speaking test. Getting the original IELTS Speaking data in the real setting is strictly not allowed and permission has not ever been given to any IELTS preparatory centres in Malaysia. This is due to privacy and confidentiality concerns of the IELTS Exam Board, British Council. During an actual IELTS speaking test, the recording is normally be done by the interlocutor with the informed consent of the students for the grading purposes if it is required. However, the original recorded data will not be given for the research purposes except for British Council use only. Therefore, for the purpose of the present study, the mock IELTS Speaking test data was used.

The mock speaking test was carried out based on the 2019 IELTS Syllabus set by British Council IELTS Malaysia in relations to its examination formats and scoring guide. The actual IELTS speaking test, which is normally conducted within 11-14 minutes, consists of three parts which are:

i. $\quad$ Part 1 on self-introduction and interview (4-5 minutes),

ii. Part 2 on individual long turn (3-4 minutes); and

iii. Part 3 on two-way discussion (4 -5 minutes) which involves a short discussion pertaining to the subject the candidate spoke about in part 2.

The scoring is based on (i) fluency and coherence (ii) vocabulary (iii) range of grammar and accuracy, as well as (iv) pronunciation. The mock test of the present study was conducted in a similar manner as that of the actual IELTS. Only in one exception that was the mock speaking test session, which somehow took up to 17 minutes due to students' propensity in comprehending and answering the questions. As it was a mock test, the interlocutor tended to probe the candidates with more questions and allowed them to speak two to three minutes longer. After the test was done, the semi-structured interviews were conducted on the students and interlocutor by one of the researchers, but no recording was made as ruled by the institution.

\section{Data Analysis}

The IELTS mock speaking test was recorded and transcribed. There were no transcription notation symbols used to transcribe the data, as the present study did not focus on verbal exchange analysis. A qualitative analysis approach based on Creswell's $(2012 ; 2013)$ was used to analyse the sentence structures using Radford's thoery $(1990 ; 1997)$ categories, namely; simple, compound, complex and compound-complex sentences (see Table 1). Each of the candidates' answers was categorised as either simple, compound, complex and compound-complex sentence. The results were then presented in a table (see Table 2 under the Analysis and Discussion section). Similarly, the interview responses were also transcribed, but not classified according to their sentence structures. The responses were used as explanations to candidates' responses in the test. 


\section{Reliability and Validity}

The spoken test transcriptions and categorisations as well responses of the semi-structured interview questions were validated by professionals from the field of languages and linguistics. The agreement, which was greater than $90 \%$ for both the transcriptions and categorisations, fulfilled the inter-rater reliability (IRR) requirement in any qualitative study (Miles, Huberman and Saldana (2014). In addition, Li (2002), Wodak (2013) and James (2019) collaboratively claimed that, with the IRR, any pattern extracted from any written textual content extract or an excerpt of spoken can represent as a whole text based on the objective of any study. Therefore, in the present study, only two or three sample of excerpts used for the analysis. As for the semi-structured interviews, the researcher took down notes of the responses of the candidates and those of the interlocutor as recording was not allowed.

\section{Analysis and Discussion}

Based on Table 2, all candidates produced an average of 15-18 sentences orally within the test time frame with one exception that is intermediate level candidate 3 (IC3), who constructed 24 sentences. This, in a way, indicates that the time limit is sufficient for the candidates to speak for a similar length. In terms of the production of the different types of sentence structures, a direct correlation between the levels of proficiency and the complexity of sentence structures can be observed. In other words, the higher the level of proficiency is, the more complex sentence structure is produced. As can be noted in Table 2, the findings are presented in a hierarchical order, that is from the simplest sentence type or structure to the most complex one. The order is first simple sentence which is then followed by the compound, the complex, and the compound-complex respectively.

In terms of the simple sentence, the foundation candidates produced the highest number, which is an average of 10 sentences. It is followed by the intermediate with an average of five and the advanced with four. For the next type of sentence, which is complex sentence, the foundation produced an average of three sentences, while the intermediate produced seven and the advanced produced four. The next type of sentence that is followed is 'complex', which is more complex than the simple as well as compound are the average for each group and also indicates a direct correlation. That is the advanced produced the highest average, which is six, followed by the intermediate with five and the foundation with three. The last category is the compound-complex sentence, which is the most complex sentence. A similar correlation is also observed i.e. the advanced produced the highest average, which is four sentences, followed by the intermediate with three and the foundation, however, did not produce such a sentence structure at all. Thus, based on the number of sentence production, it can be concluded that the sentence variations affect directly the candidates' speaking band scoring.

Table 2: Number of utterances of the Candidates of Sentence Structures

\begin{tabular}{llllll}
\hline Numbers of sentences & Simple & Compound & Complex & $\begin{array}{l}\text { Compound- } \\
\text { Complex }\end{array}$ & Total \\
\cline { 1 - 3 } Candidates & & & & & \\
\hline FC1 & $13(76.4 \%)$ & $2(11.8 \%)$ & $2(11.8 \%)$ & 0 & 17 \\
FC2 & $12(80 \%)$ & $1(6.7 \%)$ & $2(13.3 \%)$ & 0 & 15 \\
FC3 & $5(27.8 \%)$ & $8(44.4 \%)$ & $5(27.8 \%)$ & 0 & 18 \\
Average (to the nearest number) & 10 & 3 & 3 & 0 & 16 \\
IC1 & $4(22.2 \%)$ & $6(33.3 \%)$ & $5(27.8 \%)$ & $3(16.7 \%)$ & 18 \\
IC2 & $4(22.2 \%)$ & $5(27.8 \%)$ & $6(33.3 \%)$ & $3(16.7 \%)$ & 18 \\
IC3 & $7(29.2 \%)$ & $11(44.4 \%)$ & $4(17.6 \%)$ & $2(8.8 \%)$ & 24 \\
Average (to the nearest number) & 5 & 7 & 5 & 3 & 20 \\
AC1 & $6(35.3 \%)$ & $2(11.8 \%)$ & $5(29.4 \%)$ & $4(23.5 \%)$ & 17 \\
AC2 & $1(5.9 \%)$ & $6(35.3 \%)$ & $6(35.3 \%)$ & $4(23.5 \%)$ & 17 \\
Average (to the nearest number) & 4 & 4 & 6 & 4 & 17 \\
\hline
\end{tabular}

*FC- Foundation level candidate; IC- Intermediate level candidate; AC- Advanced level candidate 
DOI: https://doi.org/10.47405/mjssh.v6i5.801

\section{Discussion on Mock Speaking Test Transcriptions}

This section will discuss in details of all candidates' oral production to indicate what made them to be categorised, such as levels of proficiency.

Table 3: Foundation Candidate's Sample Responses

\begin{tabular}{lll}
\hline Candidate & Question & Answer \\
\hline FC1 & Q1- Do you have a lot of friends or & Almost all (of) my schoolmates are my \\
& prefer to have a few friends? & friends. \\
& $\begin{array}{l}\text { Q13- What kinds of things friends } \\
\text { should never do? }\end{array}$ & Friends should not lie. \\
& & \\
\hline
\end{tabular}

\section{Q- Question}

As can be seen in Table 3, the FC1's responses are basic simple structures in both Q1 and Q13. Although, Q13 was the third last question of the mock test and the candidate was expected to give more than one 'things friends should not do'. The candidate only answered 'Friends should not lie' which the structure is as follow:

$\begin{array}{ll}\text { Friends } & \text { should not lie } \\ \text { Subject } & \text { Verb }\end{array}$

In the above example, the subject is a one-word subject, while the verb is a three-one one as the candidate used the modal, 'should' in a negative form- 'should not' and the main verb is 'lie'. The subject did not include more information or elaboration on 'kinds of things friends should never do' although the question was in a plural form.

The following table offers the similar question responses by the intermediate candidate.

Table 4: Intermediate Candidate's Sample Responses

\begin{tabular}{lll}
\hline Candidate & Question & Answer \\
\hline IC1 & Q1- Do you have a lot of friends or & I have a lot of friends. I prefer real \\
& prefer to have a few friends? & friends. \\
& $\begin{array}{l}\text { Q13- What kinds of things friends } \\
\text { should never do? }\end{array}$ & $\begin{array}{l}\text { Friends should not lie. If they lie, I will } \\
\text { be upset. }\end{array}$ \\
\hline
\end{tabular}

In Table 4, although the answer for Q1 is constructed in simple sentence, the candidate offered two simple sentences, which are 'I have a lot of friends' and 'I prefer real friends'. For Q13, the answer is offered in two types of sentences, which are first in the simple type i.e. 'Friends should not lie' and second in the complex type i.e. 'If they lie, I will be upset'. The analysis of the second part of the response is as follow:

\begin{tabular}{llllll}
\hline If & they & lie, & I & will be & Upset. \\
\hline Subordinator & Subject & Verb & Subject & Verb & $\begin{array}{l}\text { Complement } \\
\text { (adjective) }\end{array}$ \\
\hline Dependent clause & & Independent clause & \\
\hline
\end{tabular}

The candidate further elaborated 'things a friend should not do' using a complex sentence as shown in the above analysis.

\begin{tabular}{lll}
\hline Candidate & Question & Answer \\
\hline AC1 & $\begin{array}{l}\text { Q1- Do you have a lot of friends or } \\
\text { prefer to have a few friends? }\end{array}$ & $\begin{array}{l}\text { Yeah. I prefer (to) have many friends, } \\
\text { who all (are) staying in China, so, I like }\end{array}$
\end{tabular}


Q13- What kinds of things friends

to make friends. should never do?

Not to betray, I think.

The response for Q1 is in a compound-complex sentence. The analysis is as follows:

Table 5. Shows the transcriptions of AC2 on similar questions.

\begin{tabular}{|c|c|c|c|c|c|c|c|c|c|c|}
\hline I & $\begin{array}{l}\text { prefer } \\
\text { to } \\
\text { make }\end{array}$ & friends & who & all & $\begin{array}{l}\text { are } \\
\text { staying }\end{array}$ & in China & so & I & $\begin{array}{l}\text { like } \\
\text { to } \\
\text { make }\end{array}$ & friends. \\
\hline Subject & Verb & Object & $\begin{array}{l}\text { Relative } \\
\text { pronoun }\end{array}$ & Subject & Verb & $\begin{array}{l}\text { Prepositional } \\
\text { phrase }\end{array}$ & & Subject & Verb & Object \\
\hline \multirow{2}{*}{\multicolumn{3}{|c|}{ Independent clause }} & \multirow{2}{*}{\multicolumn{4}{|c|}{$\begin{array}{l}\text { Dependent clause } \\
\text { Complex sentence }\end{array}$}} & Con- & & & \\
\hline & & & & & & & junction & Com! & ound $\mathrm{S}$ & atence \\
\hline
\end{tabular}

As indicated in the above analysis, the response for Q1 is made up of a complex sentence combined to a compound sentence by the conjunction, 'so'. Thus, the sentence type is a compound-complex sentence considered as the most 'complex' sentence type. As for candidate's response for Q13 response, it is made up of a complex sentence with a twist in which the dependent clause "not to betray" comes first, followed by the independent clause, 'I think'. This is a correct form as it is an oral production. If it is a written production, the arrangement will be as follows:

'I think not to betray.'

Based on the extract analysis, it can be concluded that the types of sentence production did affect the candidates' speaking bands. The foundation candidates relied primarily on simple structures, while both the intermediate and advanced had a mixture of all types of sentence structures. The advantage of the advanced candidates had over the other two groups is their balanced mixture of the different types of sentence structures in their responses ranging from an average of four to six sentences per different type of sentence structures. Whereas, the foundation students relied heavily on the simple sentences with an average of 10 sentences and the intermediate and relied heavily on the compound sentences, with average of seven sentences.

\section{Implication of the Study}

While this is a small study, it is nevertheless considered important, as the findings gained could make a positive contribution to IELTS mock speaking testing. The variety of important and effective approaches collated extends further than a testing framework.

Therefore, teachers assisting candidates for IELTS speaking test as well as normal communication situations may profit by including manifold uses to improve candidates' presentations in the most effective way. One area that teachers can concentrate on, is in the improving communication by introducing the combination of sentence structures; compound complex in IELTS speaking test. This could be achieved by initially assisting candidates improve their current knowledge and progressively going into way of discussing subject matters from common topics to precise subjects by applying a mix of sentence structures (Langn, 2018), In order to enable articulation of comprehensive thoughts. Hence, the method of using examples, describing cause and effect relationships and utilising information to sustain their stance could assist the students to maintain speaking in a rational, straightforward way in tests and communication situations by utilising those forms of sentence structures.

As such, the present study findings are important to test writers and examiners, as they may be useful in assisting them to write and produce useful input, and subsequent questions that would appeal to approaches to effectively conclude the speaking test. Conceivably, better yardsticks that define a follow-up question clearly could be configured and added to examiner in existing training modules, by 
including these sentence structures on the question on IELTS speaking test. These suggestions would also assist examiners interpret the method used to manage part 3 , in order to move past the course of 'subject-based question answer adjacency pairs' as it is normally the case in part 1 of the IELTS speaking test (Seedhouse \& Harris 2011, p. 69; Seedhouse, \& Nakatsuhara, 2018).

Apart from this, there would be IELTS speaking course modules in respective IETLS preparatory centers. The sentence structures could be integrated in existing course modules which would enhance candidate to express their comprehensive thoughts.

\section{Conclusion}

The current research was inspired by the paucity in the use of sentence structures in the speaking test sphere, particularly concerning the utilisation of combination sentence structures in articulating comprehensive thoughts. While, the sentence constructions was viewed as a vital element in writing, it was also considered as key in speaking capacity and achieving the range requirement of IELTS. This investigation acknowledges the appeal for research to study how sentence constructions perform and can be examined in test conditions to enable their application to ultimately be incorporated in scoring scales. Therefore, test takers' utilisation of approaches and the way individual sentence constructions were applied in implementing the third and final part of the IELTS speaking test was investigated.

By utilising motivated recall, comprehension of the deeper meanings of strategy employment was gained from eight international candidates who undertook the mock test. It was shown that strategies were applied constantly, which proved that sentence construction utilisation is fundamental to presentation. Additionally, the dominant utilisation of sentence construction clearly indicates that these speaking test tasks entail test takers to reflect about their thoughts and deliver a reply quickly. More so, examiners and test writers have to be equally sensitive and considerate of test takers' reaction when configuring and or managing test tasks. An evaluation between the emotional recall and candidates' oral test data showed that individual approaches have particular functions that play a role in the successful completion of the speaking test task. Approaches were inclined to be utilised in groups to attain improved excellence. Hence, integrating strategy utilisation into the teaching of speaking is of vital significance to augment students' presentation in not only testing, but also in this variable communicative context.

\section{References}

Adaninggar, S.S. (2017). A study of the mastery of complex sentences of pre-service English teachers, Ahmad Dahlan Journal of English Studies (ADJES), 4(2), 21-26.

Bachman, L. F. (1990). Fundamental considerations in language testing. Oxford: Oxford University Press.

Bachman, L. F., \& Palmer, A. (2010). Language assessment in practice. Oxford: Oxford University Press.

Baker, S.E., \& Edwards, R. (2012). How many qualitative interview is enough? National Center or Research Methods. Retrieved 28 May, 2019 from, http://eprints.nerm.ac.uk/2273/.

Barkaoui, K., Brooks, L., Swain, M., \& Lapkin, S. (2013). Test-takers' strategic behaviors in independent and integrated speaking tasks. Applied Linguistics, 34(3), 304-324.

Bunge, N. (1985). Finding the words: Conversations with writers who teach. Athens: Swallow Press, Ohio University Press.

Canale, M., \& Swain, M. (1980). Theoretical bases of communicative approaches to second language teaching and testing. Applied Linguistics, 1(1), 1-47.

Canale, M. (1983). On some dimensions of language proficiency. In J. Oller (Ed.), Issues in language testing research (pp. 333-342). Rowley: Newsbury House.

Celce-Murcia, M., \& E. Olshtain. (2000). Discourse and Context in Language Teaching.Cambridge: Cambridge University Press. 
Chris,P. (2015). Ten don'ts for the IELTS speaking test, Retrieved May 27, 2019, from https://www.britishcouncil.org/voices-magazine/ten-donts-ielts-speaking-test

Cohen, A. D. (2014). Using test-wiseness strategy research in task development. In A. J. Kunnan (Ed.), The Companion to Language Assessment (Vol. II, pp. 893-905). Hoboken: Wiley/Blackwell.

Collins, C. \& Radford, A., (2015). Gaps, ghosts and gapless relatives in spoken English. Studia Linguistica, 69 (2), 191-235.

Creswell, J. W. (2018). Qualitative inquiry and research design: Choosing among five approaches (5th ed.). Thousand Oaks, CA: Sage.

Demirezen, P. (2012). An analysis of the problem-causing structures of simple sentences for Turkish University Students. International Journal of Humanities and Social Science, 2 (3),136-146.

Gan.Z. (2013). Understanding English speaking difficulties: an investigation of two Chinese populations, Journal of Multilingual and Multicultural Development, 34(3), 231-248.

Hart, D., Grigal, M., \& Weir, C. (2010). Promising utterances: A snapshot of postsecondary education for students with intellectual disabilities across the United States, Think College Fast Facts, 1(2), 4-17.

Horwitz, E. K. (2008). Becoming a language teacher: a practical guide to second language learning and teaching. Harlow: Pearson Education.

Huang, L. S. (2013). Cognitive processes involved in performing the IELTS speaking test: respondents' strategic behaviours in simulated testing and non-testing contexts. IELTS Research Reports Online Series, 1, 1-51.

Gallois, Cindy \& Giles, H. (2015). 'Communication accommodation theory'. The International Encyclopedia of Language and Social Interaction. Wiley Online Library.

Huang, H. D. (2016). Test taking strategies in L2 assessment: the test of English for international communication speaking test. Perceptual and Motor Skills, 123(1), 64-90.

James, P. G. Ika, D.S., Hermawati,S.\& Zul,A. (2018). An analysis of compound sentences in students' writing, Advances in Social Science, Education and Humanities Research, 30 (1),341-348.

James, P. G (2019). An Introduction to Discourse Analysis: Theory and Method (4 ${ }^{\text {th }}$ Ed.) https://doi.org/10.1177/1468794116683992

Kawai, Y. (2008). Speaking and good language learners. In Lessons from Good Language Learners, Edited by C. Griffiths, 218-230. Cambridge: Cambridge University Press.

Li, D. F. (1998). It's always more difficult than you plan and imagine: Teachers' perceived difficulties in introducing the communicative approach in South Korea. TESOL Quarterly, 3(2), 677-703. doi: $10.2307 / 3588000$

Littlewood, W. (2007). Communicative and task-based language teaching in East Asian Classrooms. Language Teaching, 40, (1), 243-249.

Li. W. (2002).What do You Want Me to Say?' On the Conversation Analysis Approach to Bilingual Interaction. Language in Society, 31, 02-28.

Magoosh IELTS Blog (2018, May 27). Commons mistakes in IELTS speaking. [Msg 26]. Message posted to https://magoosh.com/ielts/ielts-speaking/common-mistakes-ielts-speaking.

Pawlak, M., E. Waniek-Klimczak, \& J. Majer. (2011). Speaking and Instructed Foreign Language Acquisition. Clevedon: Multilingual Matters.

Phaiboonnugulkij, M., \& Prapphal, K. (2013). Online speaking strategy assessment for improving speaking ability in the area of language for specific purposes: the care of tourism. English Language Teaching, 6(9), 19-29.

Mason,M.(2010). Sample size and saturation in $\mathrm{PhD}$ studies using qualitative interviews. Forum: Qualitative Social Research, 11(3), 23-36.

Miles, M.B., Huberman,A.M. \& Saldana,J. (2014). Qualitative data analysis: A method sourcebook, (3rd ed.) Washington, DC: Sage Publications.

Radford, A., Felser, C. \& Boxell, O. (2012). Preposition copying and pruning in present-day English. English Language and Linguistics, 16 (03), 403-426.

Radford, A. (1990). Transformational grammar. Cambridge: Cambridge University Press.

Radford, A. (1997). Syntactic theory and the structure of English: A minimalist approach (Cambridge Textbooks in Linguistics). Cambridge, UK: Cambridge University Press.

Richards, J. C., \&W. A. Renandya. (2002). Methodology in Language Teaching. Cambridge: Cambridge University Press. 
Sarangi, S. \& Candlin, C. N. (2011). Professional and organisational practice: A discourse/communication perspective, 3-60. In C. N. Candlin and S. Sarangi eds., Handbook of Communication in Organisations and Professions. Berlin: Mouton de Gruyter.

Seedhouse, P., \& Harris, A. (2011). Topic development in the IELTS Speaking Test. IELTS Research Reports, i, 55-110.

Seedhouse, P. \& Nakatsuhara, F. (2018). The discourse of the IELTS speaking test: interactional design and practice. Cambridge: Cambridge University Press.

Shohamy, E. (1994) The validity of direct versus semi- direct oral tests. Language Testing, 11(2), 99123.

Shkelqim, M. (2017). Function of Albanian and English sentence, European Journal of English Language Teaching, 2 (3), 83-98.

Sundari, H. (2013). Mastery of Simple Sentence Patterns in Writing Class (A Case Study of Third Semester College-Students). English Education, Journal Pendidical Bahasa Inggeris, 2(2), 111.

Steffani, S. A. (2007). Identifying Embedded and Conjoined Complex Sentences: Making it Simple. Contemporary Issues in Communication Science and Disorders, 34,44-54.

Swain, M., Huang, L. S., Barkaoui, K., Brooks, L., \& Lapkin, S. (2009), The speaking section of the TOEFL iBT (SSTiBT): test-takers'strategic behaviours, TOEFLiBT Research Report, 10. Princeton: Educational Testing Service.

Verspoor, M. \& Sauter, K. (2000). English Sentence Analysis. Amsterdam: John Benjamins Publishing Company.

Yoshida-Morise, Y. (1998). The use of communication strategies in LPIs. In R. Young \& W. He (Eds.), Talking and testing: discourse approaches to the assessment of oral proficiency (pp. 205-238). Amsterdam: John Benjamins.

Yu, Q. (2014). Various Items Causing IELTS Test-Taker's Low Performance in Mainland China: An International Joint Education Program Solution, International Conference on Global Economy, Finance and Humanities Research, 2(2). 112-122.

Wodak, R. (2013). Critical discourse analysis. London, UK; Sage.

\section{Authors' Biodata}

1. Shasthrika Baskaran obtained her Master's in Educational TESL from University Putra Malaysia and she is currently a lecturer who specialises in teaching English Proficiency for students of University of Malaya. She also specialises in presentation \& communication skills courses. She is also a part-time lecturer at a private university where she offers courses in critical thinking skills.

E-mail address: shasthrika@gmail.com, HP: +60167961583

Address: Wisma RnD University of Malaya, Jalan Pantai Baharu, Taman Bukit Pantai, 59100 Kuala Lumpur, Wilayah Persekutuan Kuala Lumpur.

2. Mohammad Nor Afandi bin Ibrahim, who obtained his $\mathrm{PhD}$ in English Language and Linguistics at University of Wollongong. He is a senior lecturer at Universiti Teknologi MARA Melaka Malaysia. His research interests include Genre Studies, Systemic Functional Linguistics, EAP, ESP and LSP.

E-mail address: afandi664@uitm.edu.my, HP: +60126844076

Address: Jabatan Bahasa Inggeris, Akademi Pengajian Bahasa, UiTM Cawangan Melaka, Kampus Alor Gajah, Km 26, Jalan Lendu, 78000 Alor Gajah, Melaka.

3. Mr Isai Amutan Krishnan is currently doing his $\mathrm{PhD}$ at the Faculty of Languages and Linguistics, University Malaya (UM), and his area of interests are in human resource development \& management, ELT, and performing arts. He is also a freelance consultant locally and abroad.

E-mail address: amuthan.isai@gmail.com, HP: +60123845100 
Address: Faculty of Languages and Linguistics, University Malaya, 50603 Kuala Lumpur

4. Ms Vasithra A/P Devamanickam is currently pursuing her degree in accountancy in University Malaya, and her area of interest is in an accounting.

E-mail address : daytheendave@gmail.com, HP: +60166880103

Address : Faculty of Business and Accountancy, University Malaya, 50603 Kuala Lumpur.

5. Nancy Andrew obtained her Diploma in Accounting from University Malaya. Her area of interests are in accounts, audit, and tax. She also deals with finances which involve in managerial decisions and cost accounting.

Email address : Stargurl1312@ gmail.com , HP: +60102284337

6. Shelen Aderina Kok works in Co-Curricular Unit, Teacher Education Institution, Kent Campus Presently, she is pursuing a $\mathrm{PhD}$ at the Faculty Psychology and Education, University of Malaysia Sabah. Her teaching experience includes teaching of various English Proficiency courses at schools and university levels. She is also currently involved in teaching TESL courses undergraduates' levels. Her research interests include pedagogical practices, teacher education and digital innovation.

Email add: shelenadekok@ipgm.edu.my, shelenadekok@yahoo.com, HP: +60138512170

Address: PG Kampus Kent Peti Surat 289207 Tuaran, Sabah

7. Saravanan Munian, obtained his degree in Indian Studies from University of Malaya in 2008. He also obtained Diploma in Education from Teachers' Training Institute. He is currently a teacher in SRJKT Ganesar Serdang, Kedah. He is also interested in research in innovative, teaching and learning. Apart from teaching, he involves in corporate social responsibility.

E-mail address: dr.saravananshiva@gmail.comHP: +60195529186

8. Dr. Manickavasagar Govindasamy obtained his $\mathrm{Ph} . \mathrm{D}$ in Languages and Linguistics from the University Malaya. His main areas of interests are in ELT within Malaysian context and English Literature mainly Asian and American.

E-mail address: manickagovindasamy@gmail.com, HP: +60126241076

Address: Faculty of Languages and Linguistics, University Malaya, 50603 Kuala Lumpur

9. Ms. Hee Sio Ching obtained her Masters in ESL from UM and is currently a trainer who specialises in English at the workplace, offering presentation \& communication skill courses. She is also a parttime lecturer with HELP university where she explores students into the field of communication, writing skills, personal branding \& career Management, ESP as well as language in public relation.

E-mail address: ansiehee@ hotmail.com, HP: +60133368175

Address: ELM Business School, HELP University, Jalan Sri Semantan 1, Off Jalan Semantan, Bukit Damansara, 50490 Kuala Lumpur

10. Mr. Vasudevan Naidu Kanan is currently a Project Manager in the Business Communication Department of O'Connor's Engineering Sdn. Bhd, Kuala Lumpur. He did his Masters in Global Business from SEGI University Kota Damansara. He used to work in CIMB Group from the department of Client Management. His research interest is in social sciences, business and information technology.

E-mail address: evanleo05@gmail.com, HP: +60129790535

Address: O’Connor's Engineering Sdn. Bhd. Bagunan O’Connor No.13 Jlaan 223, 46100 Petaling Jaya, Selangor. 